\title{
Parallel Instabilities of Long-Term Potentiation, Place Cells, and Learning Caused by Decreased Protein Kinase A Activity
}

\author{
Alexander Rotenberg, ${ }^{1}$ Ted Abel, ${ }^{2}$ Robert D. Hawkins, ${ }^{3}$ Eric R. Kandel, ${ }^{3}$ and Robert U. Muller ${ }^{1}$ \\ ${ }^{1}$ Department of Physiology, State University of New York-Brooklyn, Brooklyn, New York 11203, ${ }^{2}$ Department of Biology, \\ University of Pennsylvania, Philadelphia, Pennsylvania 19104, and ${ }^{3}$ Center for Neurobiology and Behavior and ${ }^{4}$ Howard \\ Hughes Medical Institute, Columbia University, New York, New York 10032
}

To further elucidate the links among synaptic plasticity, hippocampal place cells, and spatial memory, place cells were recorded from wild-type mice and transgenic " $R(A B)$ " mice with reduced forebrain protein kinase $A$ (PKA) activity after introduction into a novel environment. Place cells in both strains were similar during the first exposure and were equally stable for recording sessions separated by $1 \mathrm{hr}$. Place cell stability in wild-type mice was unchanged for sessions separated by $24 \mathrm{hr}$ but was reduced in $R(A B)$ mice over the longer interval. This stability pattern parallels both the reduced late-phase long-term potentiation in hippocampal slices from $R(A B)$ mice and the amnesia for context fear conditioning seen in $R(A B)$ mice 24 but not $1 \mathrm{hr}$ after training. The similar time courses of synaptic, network, and behavioral instability suggest that the genetic reduction of PKA activity is responsible for the defects at each level and support the idea that hippocampal synaptic plasticity is important in spatial memory.

Key words: hippocampus; place cell; LTP; PKA; transgenic mouse; spatial memory; spatial learning
The spatial mapping theory of O'Keefe and Nadel (1978) seeks to explain, as hippocampal functions, the ability of rodents to perform familiar spatial tasks, to learn new spatial tasks, and to store memories about spatial tasks. Their theory is based on the existence of place cells, hippocampal pyramidal cells whose activity is restricted to part of a given space called the firing field (O'Keefe and Dostrovsky, 1971). According to the mapping theory, successful performance in spatial tasks requires the coordinated, locationspecific firing of place cells (Wilson and McNaughton 1993); changes of firing patterns in a novel environment are attributable to a rapid, learning-like "remapping" process (Hill, 1978; Bostock et al., 1991; Kentros et al., 1998), and the long-term stability of new firing fields is possible because the map is stored in hippocampal memory

Spatial memory storage may depend on changes in synaptic strength initiated by activating NMDA receptors in the hippocampus. Thus, pharmacological (Collingridge et al., 1983) or genetic (Silva et al., 1992b; Mayford et al., 1995; Tsien et al., 1996) interference with NMDA receptors or with the direct consequences of activating these receptors blocks a persistent form of plasticity called long-term potentiation (LTP) at certain hippocampal synapses. The same pharmacological (Morris et al., 1986) and genetic (Silva et al., 1992a; Bach et al., 1995; Tsien et al., 1996) manipulations impair spatial memory, implying that the defective synaptic plasticity causes the defective behavioral abilities (Morris, 1989; Morris and Frey, 1997; but see Zamanillo et al., 1999).

The mapping theory predicts that impairing LTP should cause abnormalities in place cells and that these abnormalities should in turn account for the impaired spatial memory. These predictions have been confirmed in four different strains of genetically altered mice (McHugh et al., 1996; Rotenberg et al., 1996; Cho et al., 1998). Nevertheless, the causal chain from LTP to place cells to spatial behavior remains tenuous because the precise nature of the

\footnotetext{
Received Feb. 28, 2000; revised Aug. 3, 2000; accepted Aug. 3, 2000.

This work was supported by National Institutes of Health Grants NS 20686 and NS 37150 to R.U.M. and Howard Hughes Medical Institute and Mathers Charitable Trust funding to E.R.K. We thank Lawrence Eberle and Dr. Emerson Hawley for technical assistance and Dr. Clifford Kentros for critical review of this manuscript.

Correspondence should be addressed to Robert U. Muller, Department of Physiology, State University of New York-Brooklyn, 450 Clarkson Avenue, Brooklyn, NY 11203. E-mail: bob@fasthp.hippo.hscbklyn.edu.

Copyright (C) 2000 Society for Neuroscience $0270-6474 / 00 / 218096-07 \$ 15.00 / 0$
}

place cell abnormality was not predicted from the nature of the plasticity defect, nor was the behavioral deficit predicted from the place cell abnormality.

To further specify the role of synaptic plasticity in spatial memory, we recorded place cells from transgenic "R(AB)" mice in which diminished forebrain protein kinase A (PKA) activity reduces the late protein synthesis-dependent phase of LTP but leaves nearly normal the early phase of LTP (Abel et al., 1997). In hippocampus-dependent context fear conditioning, the freezing time for $\mathrm{R}(\mathrm{AB})$ mice is nearly normal $1 \mathrm{hr}$ after shock but much less than normal $24 \mathrm{hr}$ after shock, showing that the memory is unstable and suggesting that the instability is attributable to decreased PKA activity.

We therefore asked whether reduced PKA activity has parallel effects on place cell stability. If so, new place cells should form in $\mathrm{R}(\mathrm{AB})$ mice in a novel environment and be stable for at least $1 \mathrm{hr}$ but be unstable if recorded 24 hr later. We now report that precisely these patterns of place cell persistence are seen in $\mathrm{R}(\mathrm{AB})$ mice. In contrast, new place cells in wild-type mice show no loss of stability $24 \mathrm{hr}$ after exposure to a novel environment.

\section{MATERIALS AND METHODS}

The general methods are similar to those in earlier work on rats (Kubie, 1984; Muller et al., 1987) and mice (Rotenberg et al., 1996). Electrodes were constructed from $1025 \mu \mathrm{m}$ Formvar-insulated nichrome wires (California Fine Wire Co., Grover Beach, CA). The wires were arranged as two four-wire tetrodes plus two single wires threaded through a sharpened 12-mm-long 26 gauge stainless steel cannula (Small Parts Inc., Miami Lakes, FL). The cannula and wires were supported on a $3.2-\mathrm{mm}(1 / 8$ inch)-thick Teflon movable platform (Small Parts). The drive mechanism consisted of three 0-80 1/2 inch binding head machine screws (Small Parts) inserted into openings on the electrode platform and fixed with a soldered 0-80 hex nut (Small Parts). The screws were inserted into three $7 \mathrm{~mm}$ Teflon cuffs fixed to the animal's skull during surgery. The smallest increment of electrode movement was $\sim 1 / 32$ of a screw turn or $10 \mu \mathrm{m}$; a typical advance was $1 / 8$ turn or $40 \mu \mathrm{m}$.

Before experimental use the mice were handled minimally and were not preexposed to the recording environment or the food reinforcers. Surgical implantation of electrodes was identical to the method in earlier work (Rotenberg et al., 1996). The tips of the recording wire were positioned 2 $\mathrm{mm}$ lateral to midline, $2 \mathrm{~mm}$ posterior to bregma, and $800 \mu \mathrm{m}$ deep to brain surface. All surgery on animal subjects was performed under sterile conditions in accordance with National Institutes of Health and State University of New York guidelines. Before and after surgery the animals were housed in a clean, climate-controlled environment.

The signal from each electrode was amplified 10,000 times, band-pass- 
filtered at $300-10,000 \mathrm{~Hz}$, and digitized at $33 \mathrm{kHz}$. Mouse position was found by tracking a light-emitting diode (LED) attached to the electrode carrier on the animal's head. The LED position was found at a time resolution of $60 \mathrm{~Hz}$ and a spatial resolution of six bits; each of the 4096 pixels was $1.4 \mathrm{~cm}$ on a side.

Each mouse was used only once in the experiment, which consisted of four parts: (1) initial screening for cells in the mouse's home cage; the screening was done in the dark with the cage inside the recording room; (2) training in a novel recording cylinder; (3) checking again for useful cell waveforms in the home cage, also in the dark with the cage in the recording room; and (4) formal recordings in a second novel recording cylinder.

For cell screening, the electrode carrier was lowered $40 \mu \mathrm{m} / \mathrm{d}$, and electrical activity on all wires was inspected for single-unit activity. We saw a tendency for the first waveforms encountered in both wild-type and mutant mice to be brief positive-negative spikes in which the duration of both phases was $\sim 200-250 \mu \mathrm{sec}$. These waveforms, which may be generated by fibers in the alveus, often had the discharge properties of postsubicular head direction cells (Taube et al., 1990). With further electrode advances, there was a tendency to see negative-positive action potentials whose initial phase was $<300 \mu \mathrm{sec}$ and whose second phase was generally $>400 \mu$ sec. These units never generated complex spikes, always fired at an appreciable $(>10 \mathrm{~Hz})$ rate, showed increased firing during locomotion, and showed positional firing rate modulation of $\sim 2: 1$. Because of their depth and other characteristics, these units are taken to be "theta" cells (Ranck, 1973; Kubie et al., 1990). The positional firing patterns of theta cells (presumed inhibitory interneurons) strongly resembled those in rats. Still deeper, there was a tendency to see negative-positive action potentials whose initial phase was $>300 \mu$ sec. In addition to single, "simple spikes," cells with relatively long-duration initial phases often fired high-frequency bursts of action potentials of decrementing amplitude and were taken to be complex spike cells (Ranck, 1973), anatomically pyramidal cells of Ammon's horn (Fox and Ranck, 1975; O'Keefe, 1976). In agreement with a great deal of earlier work, many of the complex spike cells were place cells. Theta cells and complex spike cells were often seen at the same time.

The second, training part of the experiment was initiated once two or more complex spike cells were discriminated during screening; discrimination was done with the classification software provided by Datawave Inc (Longmont, CO). The amplitude of the simple spikes of each had to be at least $150 \mu \mathrm{V}$, which yields a signal-to-noise ratio of $\sim 5: 1$. No further electrode advances were made after this criterion was satisfied. From previous experience, leaving the electrodes for an extended period, in this case the two-day training period, enhances the likelihood that discriminated waveforms will be stable.

Training consisted of three 16 min sessions done as mice foraged for food powder inside a 49-cm-diameter, 34-cm-high cylindrical apparatus. The apparatus was centered inside a set of cylindrical curtains $2 \mathrm{~m}$ in diameter that provided visual isolation of the uncontrolled stimuli in the small recording room from the mouse. The floor of the cylinder was gray photographic backdrop paper that was replaced before each session. The food was scattered onto the floor before each session, and none was added during the session. The cylinder used for training was gray except for a white card that occupied $90^{\circ}$ of the cylinder circumference. The first training session was done $\sim 1 \mathrm{hr}$ after successful detection of two or more complex spike cells, a second $24 \mathrm{hr}$ later, and a third $1 \mathrm{hr}$ after the second. These training sessions served to familiarize the mice with the general recording conditions so that the data were acquired when novelty was restricted to new visual stimuli and not to an entirely new set of circumstances.

The next day, for part 3 of the protocol, the mouse was reconnected to confirm the presence of two or more complex spike cells with at least 150 $\mu \mathrm{V}$ waveforms. If no adequate activity was seen at this time, the mouse was removed from the experiment. If such activity was seen, the final, experimental part of the protocol was done, regardless of whether the waveforms were differently shaped or on different electrodes than was seen previously. The last part of the protocol consisted of three $16 \mathrm{~min}$ sessions done as mice again foraged for food inside a second 49-cm-diameter, 34-cm-high cylinder located in the same spot as the training cylinder. The inside of this cylinder was white except for a black cue card that occupied $90^{\circ}$ of arc (Fig. $1)$. The appearance of this cylinder was chosen from previous work in rats (Kentros et al., 1998), and pilot experiments in mice that suggested it would act as a distinct environment from the gray cylinder with the white card. The first session in the white cylinder was done just after rescreening $(t=0)$, the second $24 \mathrm{hr}$ later $(t=24)$, and the third $1 \mathrm{hr}$ after the second $(t=25)$. All reported data come from the three sessions in the white cylinder.

To construct firing rate maps and to analyze positional firing patterns, the total time the LED was detected in each pixel and the number of spikes fired in each pixel were accumulated. A time-averaged firing rate was calculated for each pixel by dividing the number of spikes in each pixel by the dwell time in that pixel. Color-coded firing rate maps were used to visualize positional firing rate distributions. Pixel rates were sorted in ascending order, partitioned into six categories and coded in the sequence yellow, orange, red, green, blue, and purple. The firing is exactly zero for yellow pixels. Unvisited pixels in the cylinder and pixels outside the cylinder are coded in white.

Coherence was used to estimate the strength of the positional signal from place cells (Kubie et al., 1990). Coherence is a nearest neighbor

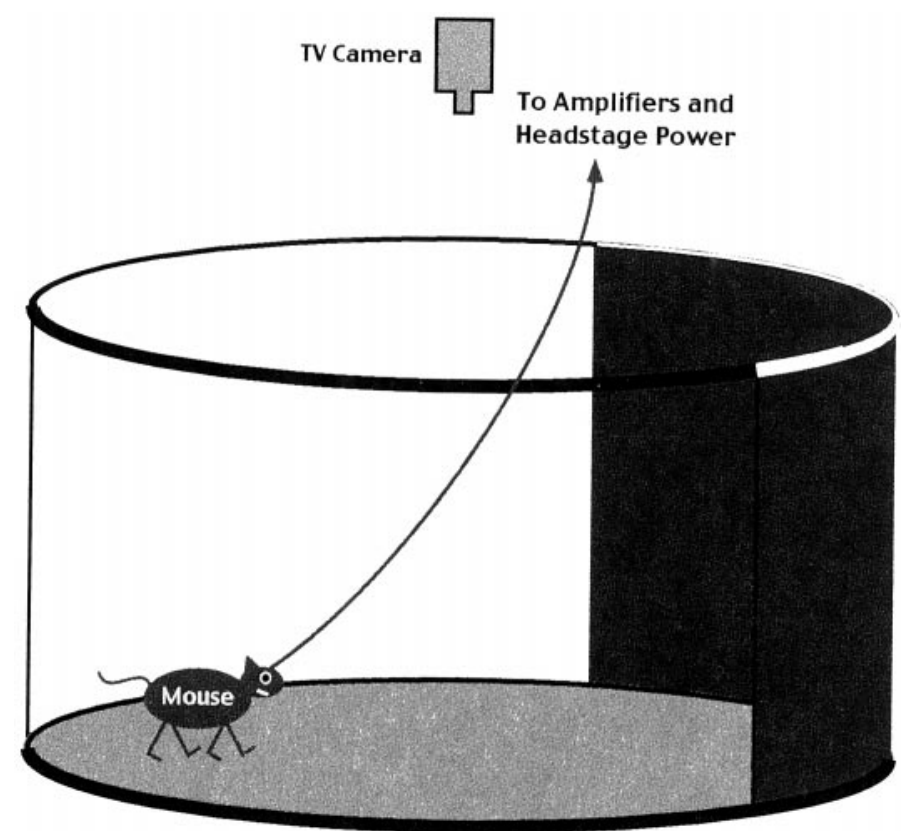

Figure 1. Recording setup. A mouse with an implanted recording electrode is connected to an amplifier head stage and cable, which are then connected to the data acquisition system (see Materials and Methods). Place cells were recorded as mice foraged for food powder on the floor of a plywood cylinder. The cylinder was surrounded by dark ceiling-to-floor curtains. Four $25 \mathrm{~W}$ bulbs were symmetrically positioned overhead, and the recording apparatus was placed in an electrically shielded, closed-door recording chamber. The only deliberate orienting cue was a card spanning $90^{\circ}$ of arc placed on the inside wall of the cylinder.

two-dimensional autocorrelation that measures the local smoothness of a positional firing pattern. To calculate coherence, a list of the firing rate in each pixel and a corresponding list of the average firing rate in the eight nearest neighbor pixels are constructed. The reported value is the $z$ transform of the correlation coefficient for these lists.

To measure the stability of place cell positional firing patterns, we calculated a similarity score for each of the three pairs of sessions. The similarity is the $z$ transform of the pixel-by-pixel correlation obtained by superimposing the positional firing pattern in one session against that of the second session (Kubie et al., 1990).

\section{RESULTS}

To obtain comparably discriminable waveform samples in wildtype and $\mathrm{R}(\mathrm{AB})$ mice, we recorded a CA1 pyramidal cell if and only if the amplitude of its extracellular waveform exceeded 150 $\mu \mathrm{V}$. The fraction of pyramidal cells considered place cells was assessed first by inspecting color-coded firing rate maps for restricted, simply shaped regions called "firing fields" and extremely quiet out-of-field regions. Of 29 cells recorded from 8 wild-type mice, $18(62.1 \%)$ were judged to be place cells; of 35 cells recorded from $11 \mathrm{R}(\mathrm{AB})$ mice, $21(60.0 \%)$ were judged to be place cells. Thus, the reduced forebrain PKA activity of $\mathrm{R}(\mathrm{AB})$ mice does not eliminate place cells, which are also preserved after other genetic manipulations of NMDA-based LTP (McHugh et al., 1996; Rotenberg et al., 1996; Cho et al., 1998).

A quantitative way of deciding whether a pyramidal cell is a place cell is to measure the local smoothness of the positional firing rate pattern with coherence (see Materials and Methods); weak or noisy positional firing patterns have low coherence, whereas patterns with crisp firing fields have high coherence (Fig. 2). We used a coherence value of 0.26 to distinguish place cells from other pyramidal cells, the same value used by Rotenberg et al. (1996). On this basis, 19 of 29 wild-type cells $(65.5 \%)$ and 22 of $35 \mathrm{R}(\mathrm{AB})$ cells $(62.9 \%)$ were called place cells in the first recording session for each cell. Moreover, there is excellent agreement for deciding whether a unit is a place cell according to inspection of rate maps and according to coherence. The fraction of cells for which these two methods were in agreement is plotted in Figure 3 as a function 

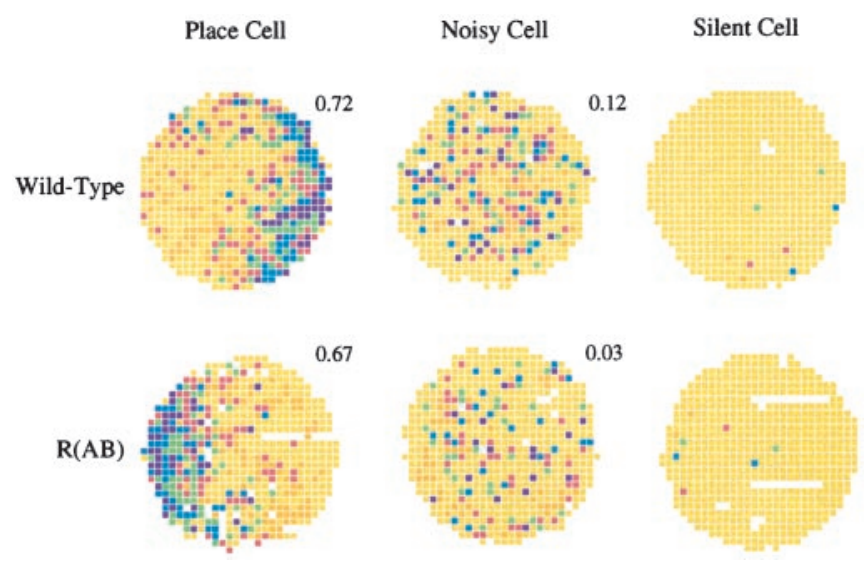

Figure 2. Selection of the place cell sample. Example color-coded firing rate maps are shown for the three functional classes of hippocampal pyramidal cells (place, silent, and noisy) recognized from positional recordings (the same types are seen in CaMKII-Asp ${ }^{286}$ mutants; Rotenberg et al., 1996). The examples in the top row are from wild-type mice, and those in the bottom row are from $\mathrm{R}(\mathrm{AB})$ mutants. The coherence value for each cell is shown next to the map. Yellow pixels represent an average firing rate of exactly zero in each rate map. Median firing rates (spikes per second) coded by the remaining pixels are as follows: wild-type place (tan, 0.66 ; red, 1.62; green, 3.10; blue, 3.00; purple, 3.37); wild-type noisy (tan, 0.43; red, 0.36 ; green, 1.23; blue, 1.30; purple, 2.98); wild-type silent (tan, 0.23; red, 0.39; green, 0.72; blue, 1.42); mutant place (tan, 0.77; red, 2.30; green, 3.22; blue, 7.62; purple, 13.34); mutant noisy (tan, 0.31 ; red, 0.63 ; green, 0.97 ; blue, 1.43 ; purple, 2.14); and mutant silent (tan, $0.71 ;$ red, 1.63; green, 2.31 ; blue, 3.33 ). The wild-type place cell has a firing field against the cylinder wall centered on 3 o'clock; its grand average firing rate was $1.48 \mathrm{spikes} / \mathrm{sec}$. The noisy wild-type cell fired at a relatively low rate $(0.61 \mathrm{spikes} / \mathrm{sec})$ everywhere in the cylinder; there was no tendency to discharge preferentially in a certain region. The silent cell fired only nine spikes (average rate, $0.009 \mathrm{spikes} / \mathrm{sec}$ ) during the entire 16 min recording session. The $\mathrm{R}(\mathrm{AB})$ place cell has a field against the wall at 9 o'clock; the grand average firing rate for this cell was $2.29 \mathrm{spikes} / \mathrm{sec}$. The noisy $\mathrm{R}(\mathrm{AB})$ cell fired at an overall average rate of 0.25 spikes/sec; the overall rate of the $R(A B)$ silent cell was 0.02 spikes $/ \mathrm{sec}$.

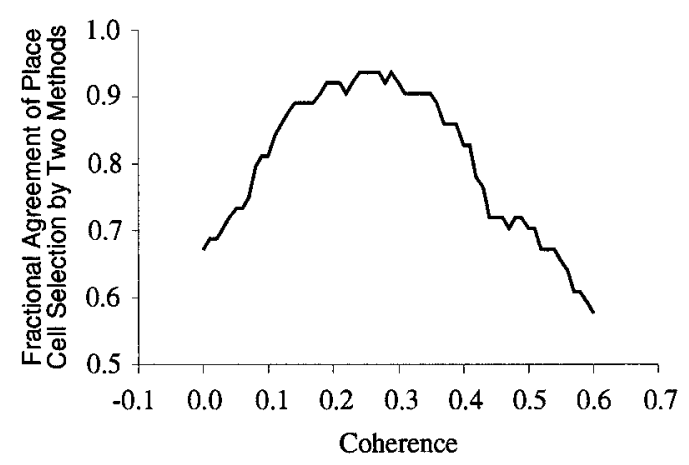

Figure 3. Agreement of place cell selection by inspection of firing rate maps and by coherence. The line shows the fraction of cells for which there is agreement between categorization of place cells by visual inspection of rate maps and by coherence plotted as a function of increasing coherence. The agreement between the subjective and objective measures reaches a peak of 0.94 in the coherence range $0.22-0.28$. The coherence cutoff for a place cell was taken as 0.26 , the same value used in an earlier study (Rotenberg et al., 1996); using coherence as the only criterion is a simplification of the earlier method.

of the coherence value used to distinguish place cells from nonplace cells. That is, using the same set of subjective decisions, the coherence cutoff was systematically varied from 0.00 to 0.60 , and the fraction of cells for which the two methods agreed was recalculated for each coherence value. The relationship peaks at $93.8 \%$ over the coherence range from 0.22 to 0.28 and declines for smaller and larger coherences; the almost exact agreement in this range indicates that the objective method accurately captures the notions we have developed of which sorts of firing patterns are generated by place cells.

We next asked whether wild-type and $R(A B)$ place cells differed in quality according to several measures of positional firing patterns for the first recording session for each cell. In earlier work, we found that the mean coherence of place cells in wild-type mice was higher than that of place cells in $\mathrm{Ca} /$ calmodulin-dependent protein kinase II (CaMKII)-Asp ${ }^{286}$ transgenic mice. Here, the absence of a reliable difference between the mean coherence of 0.576 for wild-type mice and of 0.540 for $\mathrm{R}(\mathrm{AB})$ mice $(t=0.57$; $\mathrm{df}=39 ; p=$ $0.57)$ indicates that expression of the $\mathrm{R}(\mathrm{AB})$ transgene does not disrupt the quality of positional firing patterns. The mean peak firing rates of 20.6 spikes/sec for $\mathrm{R}(\mathrm{AB})$ place cells and 23.2 spikes/sec for wild-type place cells were not reliably different $(t=$ 0.43 ; df $=39 ; p=0.67)$. Similarly, the grand average firing rates (number of spikes per total recording time) of 2.27 spikes/sec for wild-type place cells and 1.48 spikes/sec for $\mathrm{R}(\mathrm{AB})$ cells were not significantly different $(t=1.43 ; \mathrm{df}=39 ; p=0.16)$. Finally, firing field area normalized by the number of visited pixels did not reliably differ between wild-type mice $(0.442)$ and $\mathrm{R}(\mathrm{AB})$ mice $(0.295)(t=1.78 ; \mathrm{df}=39 ; p=0.084)$. Thus, the properties of place cells in wild-type and $\mathrm{R}(\mathrm{AB})$ mice are very alike when compared in single sessions.

Finally, we compared the stability of place cells in wild-type and $\mathrm{R}(\mathrm{AB})$ mice over long (24 hr) and short (1 hr) intervals. Examples of positional firing patterns from five wild-type place cells are shown for the three sessions in Figure $4 A$. The first three cells (inside a $b o x$ ) were simultaneously recorded from an individual wild-type mouse; the final two cells were each recorded from two other wild-type mice. Only the firing pattern of the first cell in Figure $4 A$ was unstable over the initial $24 \mathrm{hr}$ interval. Furthermore, all the example cells in Figure $4 A$ appeared stable over the final 1 hr interval. Thus, it was not uncommon for well-isolated wild-type cells to be unstable over the $24 \mathrm{hr}$ interval, and some cells were unstable even over the $1 \mathrm{hr}$ interval (data not shown). This coexistence of stable and unstable place cells in wild-type mice justifies the analysis of stability on a per cell rather than per mouse basis.

A selection of five place cells in $\mathrm{R}(\mathrm{AB})$ animals is shown in Figure $4 B$. Again, the first three cells were simultaneously recorded from a single mouse, whereas the last two were from two other $\mathrm{R}(\mathrm{AB})$ mice. For all five cells, the positional firing patterns (including silence for cell 4 ) at the 24 and $25 \mathrm{hr}$ time points strongly resemble each other, suggesting that the $\mathrm{R}(\mathrm{AB})$ place cells are as stable as wild type place cells over the $1 \mathrm{hr}$ interval. In contrast to the relative stability at $1 \mathrm{hr}$ for both wild-type and $\mathrm{R}(\mathrm{AB})$ mice and at $24 \mathrm{hr}$ for wild-type mice, only one of the five $\mathrm{R}(\mathrm{AB})$ examples appeared to be stable over the $24 \mathrm{hr}$ interval.

The impressions of relative stability gained from inspection of rate maps were confirmed by calculating the similarity of the positional firing rate distributions in pairs of sessions. Histograms of the similarities for wild-type and $\mathrm{R}(\mathrm{AB})$ place cells over the 24 and $1 \mathrm{hr}$ intervals are shown in Figure 5; also shown are the means and variances for each distribution; $F$ tests revealed no differences among the variances. In addition, as shown by $t$ tests for correlation coefficients, the stability over the $24 \mathrm{hr}$ interval was not well predicted from the firing rate at the $0 \mathrm{hr}$ time point for either wild-type or $\mathrm{R}(\mathrm{AB})$ place cells. For wild-type mice, the correlation was 0.36 with $17 \mathrm{df}$; the associated $p=0.13$. For $\mathrm{R}(\mathrm{AB})$ mice, the correlation was -0.025 with $20 \mathrm{df}$; the associated $p=0.91$.

Figure 6 shows the average similarities and SEM for 24 and $1 \mathrm{hr}$ intervals in wild-type and $\mathrm{R}(\mathrm{AB})$ mice. $t$ tests for six possible pair-wise comparisons of similarity revealed two key results. First, the similarities for the $\mathrm{R}(\mathrm{AB})$ place cells over the $24 \mathrm{hr}$ interval are reliably lower than for the $1 \mathrm{hr}$ interval for the same cells $(t=3.117$; df $=59 ; p<0.003)$ and also lower than for the wild-type cells at either the $24 \mathrm{hr}(t=2.493$; df $=54 ; p<0.016)$ or $1 \mathrm{hr}(t=2.096$; $\mathrm{df}=52 ; p=0.04)$ interval. Second, the mean similarity at $1 \mathrm{hr}$ for $\mathrm{R}(\mathrm{AB})$ cells was not reliably different than for wild-type cells at either the 1 or $24 \mathrm{hr}$ interval ( $p=0.59$ and 0.61 , respectively).

The equal mean similarity of wild-type place cells for the 24 and $1 \mathrm{hr}$ intervals suggests there is little decay of stored information, whereas the lower mean similarity of $\mathrm{R}(\mathrm{AB})$ place cells for the 24 hr interval implies a memory defect. These conclusions are based 


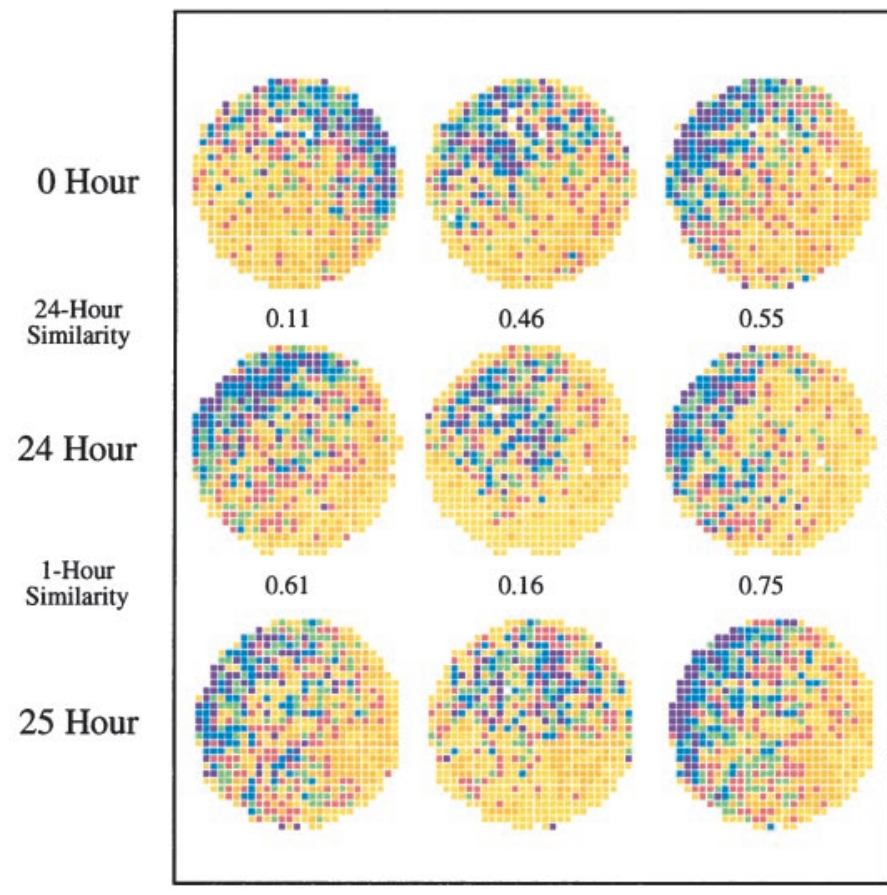

Mouse 1

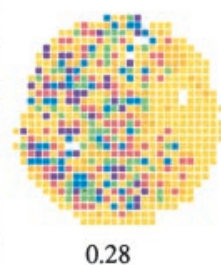

0.28

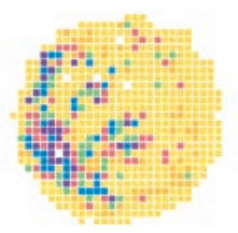

0.31

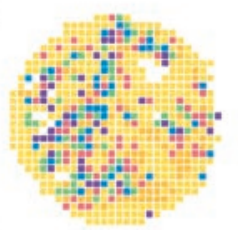

Mouse 2
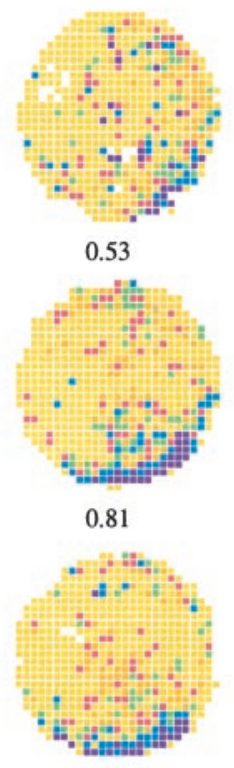

Mouse 3

B R(AB) Place Cells

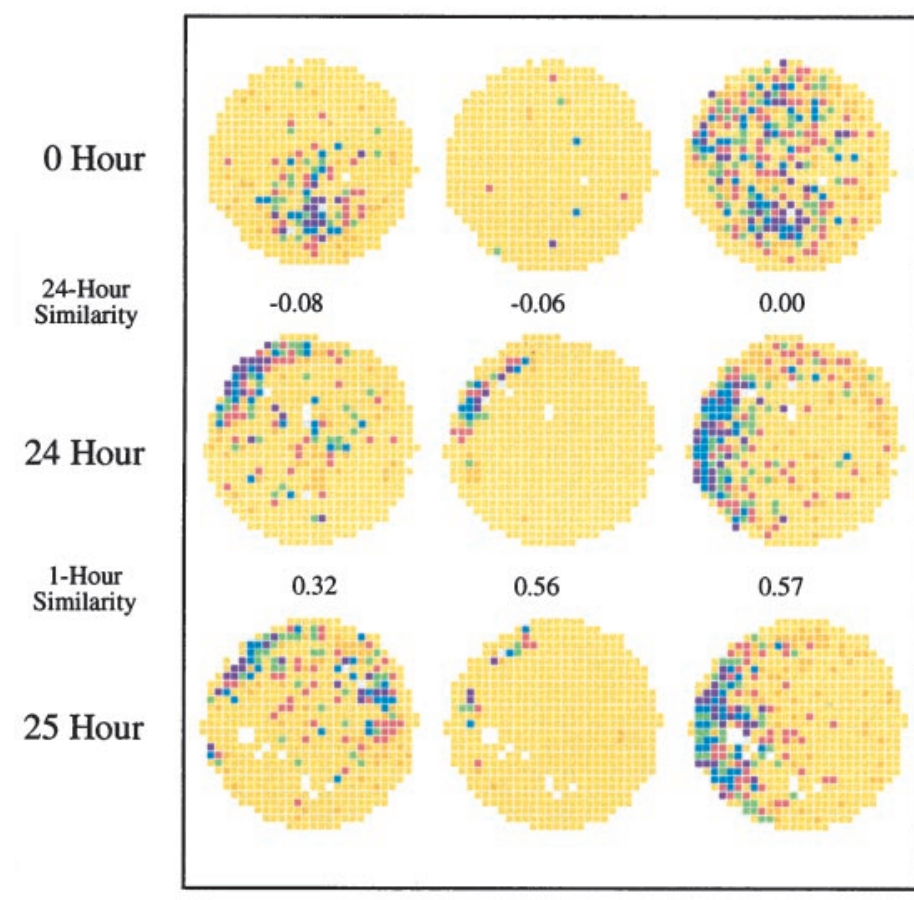

Mouse 1
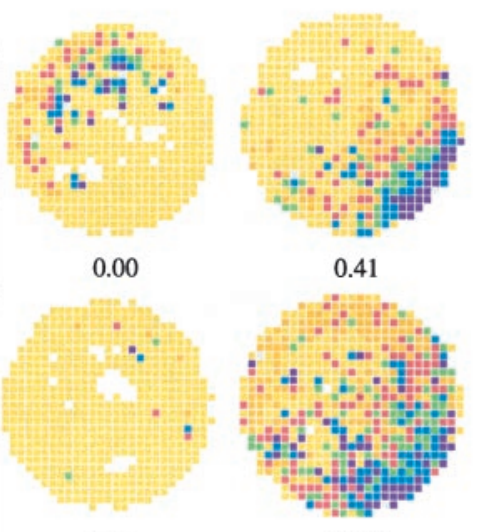

0.16

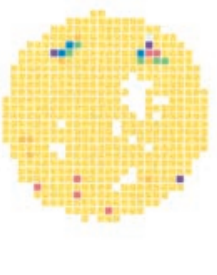

Mouse 2

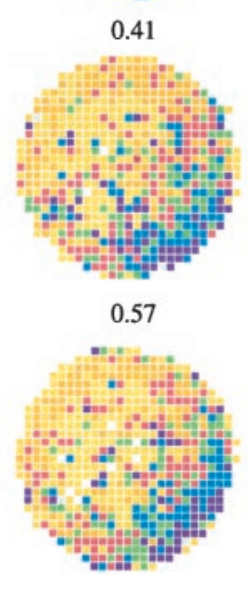

Mouse 3

Figure 4. Examples of firing pattern stability at different intervals between recordings. $A$, Five wild-type place cells recorded at $t=0, t=24$, and $t=$ $25 \mathrm{hr}$. The three place cells in the black frame were recorded simultaneously from one mouse; the other two cells were recorded from two other wild-type mice. The recordings at $t=0 \mathrm{hr}$ were made after each mouse was put for the first time into a novel white cylinder with a black card; between recordings the mouse was in its home cage. Stability values are provided between pairs of rate maps. The positional firing pattern was stable for each cell over the $1 \mathrm{hr}$ interval. For four of the five cells the positional firing pattern was also stable over the $24 \mathrm{hr}$ interval. The exception is the one of three simultaneously recorded cells in the leftmost column. The inconsistent firing pattern of this cell corresponds to a low stability value for the 24 hr session pair. Note also that the crisp field in the rightmost column showed some rotational instability. Both strong and rotation-only field instability are more likely in wild-type mice than in rats. This decreased field stability in wild-type littermates provides a noisier background for asking about instability in mutant mice and 

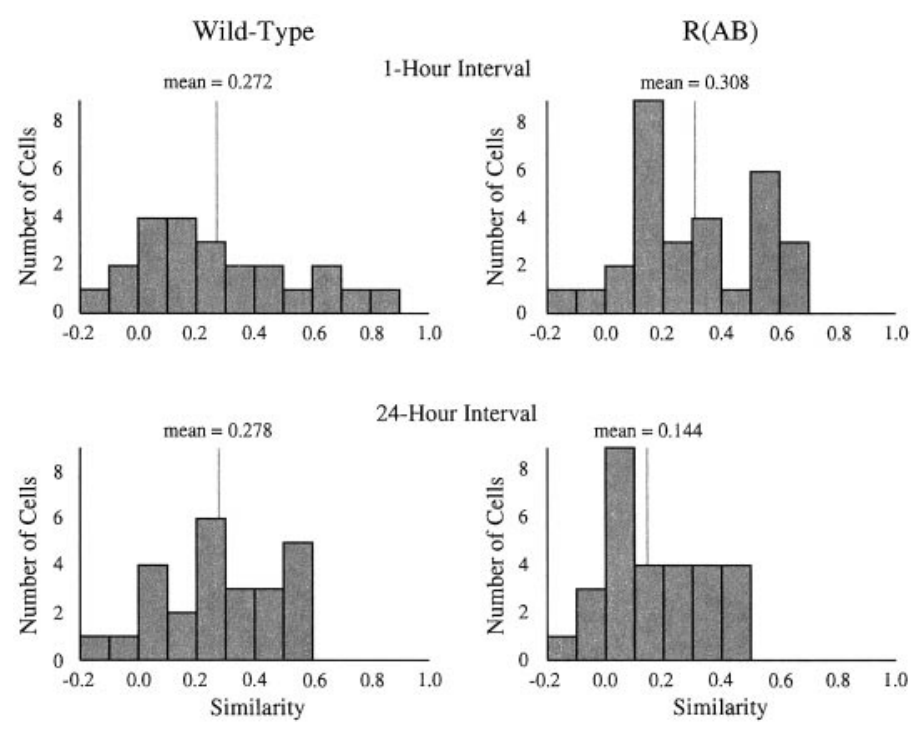

Figure 5. Distributions of similarity values over intervals of 1 and $24 \mathrm{hr}$. Histograms of firing pattern similarity are shown for wild-type and $R(A B)$ cells. $F$ tests show that the variances of similarity are not reliably different for cells in either mouse strain at either time interval.

on comparisons within a strain and therefore cannot be secondary to possible strain differences for place cells that our analysis did not detect. The finding that the mean similarity for $\mathrm{R}(\mathrm{AB})$ place cells at the $1 \mathrm{hr}$ interval is equal to the similarity for the wild-type place cells at either interval further implies that memory in $\mathrm{R}(\mathrm{AB})$ mice is unimpaired over short intervals.

We also compared the similarity of firing patterns at 24 and $1 \mathrm{hr}$ intervals for individual $\mathrm{R}(\mathrm{AB})$ cells with the similarity between the $24 \mathrm{hr}$ session for each cell and the $1 \mathrm{hr}$ session for a randomly chosen second cell. The mean similarity between unrelated 24 and $1 \mathrm{hr}$ firing patterns was 0.041 , reliably lower than the mean similarity of the individual cells. Thus, some information about field location is preserved for $24 \mathrm{hr}$ in $\mathrm{R}(\mathrm{AB})$ mice.

\section{DISCUSSION}

The demonstration that $\mathrm{R}(\mathrm{AB})$ place cells are as stable as wildtype place cells over a $1 \mathrm{hr}$ interval but less stable over a $24 \mathrm{hr}$ interval provides new evidence linking the molecular processes underlying synaptic plasticity to behavioral learning. We think expression of the $\mathrm{R}(\mathrm{AB})$ transgene has three parallel effects: (1) At the synaptic level it hinders or prevents establishment of the protein synthesis-dependent late phase of LTP without affecting early phase LTP. (2) At the network level, R(AB) expression reduces the stability of place cells $24 \mathrm{hr}$ after they form in a novel environment. We suggest that this reduced long-term stability is a consequence of the reduced late-phase LTP. We further suggest that the lack of effect of $\mathrm{R}(\mathrm{AB})$ expression on place cell stability at $1 \mathrm{hr}$ implies that either early-phase LTP or a non-NMDA plasticity mechanism might be sufficient to transiently store memory. (3) At the behav-

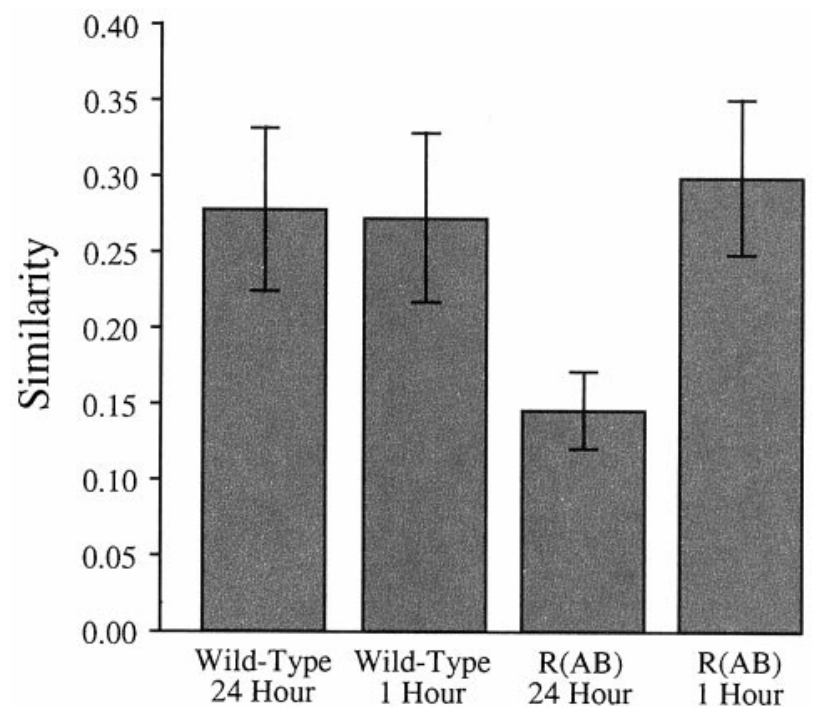

Figure 6. Average similarities and SEM. According to $t$ tests, all differences between the average similarity of $\mathrm{R}(\mathrm{AB})$ place cells recorded at $24 \mathrm{hr}$ intervals (second column) and the other average similarities are significant at $p \geq 0.05$; none of the other differences is significant.

ioral level $\mathrm{R}(\mathrm{AB})$ expression weakens or prevents memory for a hippocampal-dependent form of aversive conditioning at $24 \mathrm{hr}$ but does not affect memory at $1 \mathrm{hr}$. It is the similar time course over which information is lost at the synaptic, network, and behavioral levels that suggests that all three deficits are consequences of the reduced forebrain PKA activity caused by expression of $R(A B)$. In future studies, connections among LTP, single cells, and behavior could be strengthened further by using an explicitly spatial task that can be learned at a rate comparable with that of contextual fear conditioning or by finding a neuronal correlate of contextual fear conditioning for pyramidal cells.

The weak but detectable retention of firing patterns for $24 \mathrm{hr}$ is parallel to the small amount of freezing seen in $\mathrm{R}(\mathrm{AB})$ mice $24 \mathrm{hr}$ after context fear conditioning and therefore suggests a basis for the partial memory. When the amnesia of $\mathrm{R}(\mathrm{AB})$ mice for context fear conditioning is studied at higher time resolution, freezing reaches a minimum $3 \mathrm{hr}$ after training and decreases no more (Bourtchouladze et al., 1998). If place cell stability follows a similar time course, the argument that amnesia for context directly reflects stability of hippocampal pyramidal cell firing correlates would be enhanced.

The properties of place cells are quite different in $\mathrm{R}(\mathrm{AB})$ mice than in transgenic mice with constitutively active CaMKII-Asp ${ }^{286}$ (Rotenberg et al., 1996). In R(AB) mice, place cells are abnormal only in their more rapid decay of stability. In contrast, in CaMKII$\mathrm{Asp}^{286}$ mice place cells were a smaller fraction of the pyramidal cells; they fired at lower rates and had less coherent fields that were unstable over very brief intervals.

Average coherence values for CaMKII-Asp ${ }^{286}$ mice, the subject

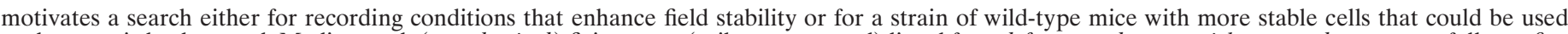

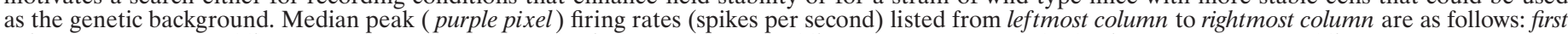

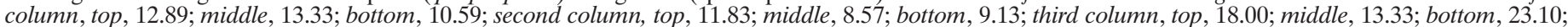

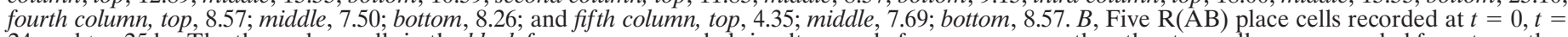

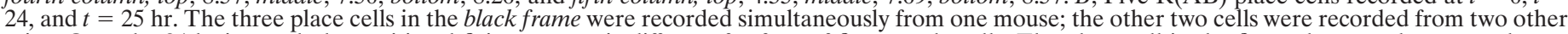

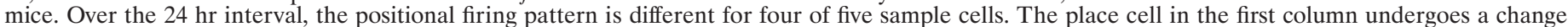

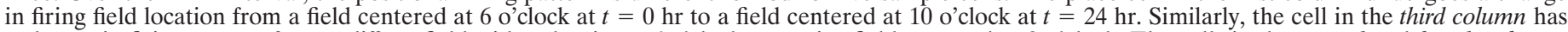

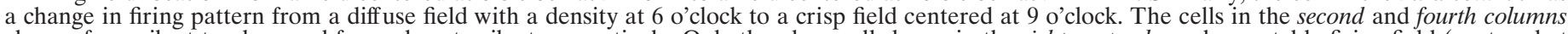

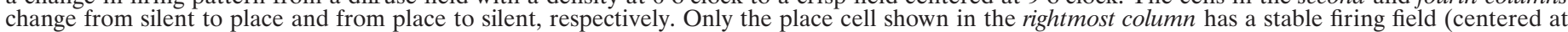

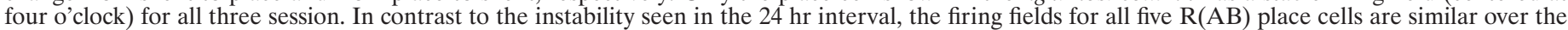

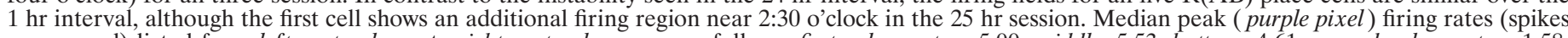

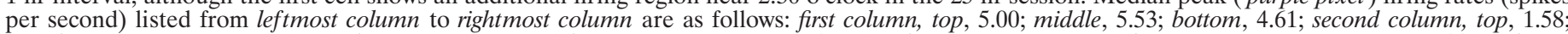

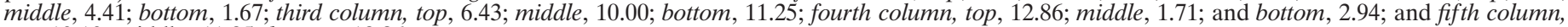
top, 10.10; middle, 11.25 ; bottom, 12.86 . 
of an earlier experiment, were recalculated for this study. In the original work (Rotenberg et al., 1996), the coherence values were averages across four sessions for each cell. Recalculation of the mean coherence for the first session for each cell was done to allow comparisons with the present study. The mean was 0.668 for wild-type cells and 0.421 for CaMKII-Asp ${ }^{286}$ mice. The probability that these means are equal according to a $t$ test is $p=0.002(t=$ 3.31 ; $\mathrm{df}=26)$. The mean coherence of place cells for wild-type mice in the CaMKII-Asp ${ }^{286}$ study was not different from the mean coherence of place cells in either wild-type or $\mathrm{R}(\mathrm{AB})$ mice in the present study. Thus, genetic modifications of two different protein kinases implicated in LTP cause very different place cell phenotypes. This illustrates how a genetic analysis may be used to examine the means by which mechanisms of synaptic modification operate at the network level in intact animals.

The role of late-phase LTP in stabilizing newly formed place cells described here is in excellent agreement with the effects of pharmacological blockade of NMDA receptors on rat place cells. ( \pm )-3-(2-carboxypiperazine-4-yl)-propyl-1-phosphonic acid (CPP), a competitive antagonist of NMDA receptors whose action lasts $\sim 3 \mathrm{hr}$, was injected before place cells were repeatedly recorded over $2 \mathrm{~d}$, alternating between a familiar cylinder and a novel cylinder (Kentros et al., 1998). Acute blockade of NMDA receptors never altered place cells in the familiar environment, nor did it prevent formation or short-term $(1.5 \mathrm{hr})$ stability of place cells in the novel environment. However, additional recordings made $24 \mathrm{hr}$ later, when CPP had ceased to act, showed that the original positional firing patterns in the novel environment were replaced by yet another set of patterns. Recordings from saline-injected rats the next day showed that the original firing patterns in the novel environment were stable.

Thus, genetic suppression of PKA activity and pharmacological blockade of NMDA-based LTP have remarkably similar effects on place cells. In each case, place cells develop normally in a novel environment and are stable for at least 1 or $2 \mathrm{hr}$ but are unstable 24 hr after the first exposure (Kentros et al., 1998). These convergent results can be explained by considering the common effects of the genetic and pharmacological perturbations. Blocking NMDA channels affects LTP at its first step, before the entry of $\mathrm{Ca}^{2+}$, whereas reduction of PKA activity leaves early-phase LTP intact but prevents late-phase LTP. We infer that only the late, proteindependent phase of NMDA-based LTP is crucial for the long-term stability of place cells. An additional inference is that place cells are formed de novo on entry to a novel environment and are not predisposed to be triggered by certain features in the environment, as would be expected of high-order sensory cells; otherwise the fields would not change with time. The pharmacological results also imply that place cell formation and initial stability may require a non-NMDA-based form of synaptic plasticity.

Can transiently stable place cells in a novel environment support spatial learning if the task can be acquired before late-phase LTP becomes essential? Naive rats exposed to NMDA channel blockers do poorly in the Morris swimming task even if training takes place within $2 \mathrm{hr}$ (Saucier and Cain, 1995). This impairment is alleviated by several forms of nonspatial pretraining (Bannerman et al., 1995; Oh et al., 1999), suggesting that performance deficits do not reflect purely navigational problems and therefore may not test whether transiently stable place cells are sufficient for spatial problem solving. In a delayed match-to-position variant of the swimming task, rats learned without drug and were then tested after either chronic or acute intracerebroventricular administration of APV, an NMDA channel blocker (Steele and Morris, 1999). Performance after a very brief delay (15 sec) was nearly asymptotic, but longer delays (20 or $120 \mathrm{~min}$ ) caused considerable impairment. Thus, in circumstances in which stable place cells are expected to exist, blockade of NMDA channels causes a delay-dependent deficit in the ability to remember the location of a movable goal platform. In our experiments, we observed no decay of place cell firing patterns with a correspondingly short time course. Perhaps a reduction of the spatial signal too small to be seen with our methods can cause a deterioration of behavioral capacity. Alternatively, memory decay with a time course of at most 20 min may not occur in our simple food-gathering task but might be visible in place cell properties if the animal had to solve a spatial problem. The broad goal of using place cells to provide a natural bridge from the artificial phenomenon of LTP to behavioral learning will therefore also require characterization of place cell properties during acquisition and performance of standard spatial tasks.

\section{REFERENCES}

Abel T, Nguyen PV, Barad M, Deuel TA, Kandel ER, Bourtchouladze R (1997) Genetic demonstration of a role for PKA in the late phase of LTP and in hippocampus-based long-term memory. Cell 88:615-626.

Bach ME, Hawkins RD, Osman M, Kandel ER, Mayford M (1995) Impairment of spatial but not contextual memory in CaMKII mutant mice with a selective loss of hippocampal LTP in the range of the theta frequency. Cell 81:905-915.

Bannerman DM, Good MA, Butcher SP, Ramsay M, Morris RG (1995) Distinct components of spatial learning revealed by prior training and NMDA receptor blockade. Nature 378:182-186.

Bostock E, Muller RU, Kubie JL (1991) Experience-dependent modifications of hippocampal place cell firing. Hippocampus 1:193-205.

Bourtchouladze R, Abel T, Berman N, Gordon R, Lapidus K, Kandel ER (1998) Different training procedures recruit either one or two critical periods for contextual memory consolidation, each of which requires protein synthesis and PKA. Learn Mem 5:365-374.

Cho Y, Giese KP, Tanila H, Silva AJ, Eichenbaum H (1998) Abnormal hippocampal spatial representations in alphaCaMKIIT286A and CREBalphaDelta mice. Science 297:867-869.

Collingridge GL, Kehl SJ, McLennan H (1983) Excitatory amino acids in synaptic transmission in the Schaffer collateral-commissural pathway of the rat hippocampus. J Physiol (Lond) 334:33-46.

Fox SE, Ranck Jr JB (1975) Localization and anatomical identification of theta and complex spike cells in dorsal hippocampal formation of rats. Exp Neurol 49:299-313.

Hill AJ (1978) First occurrence of hippocampal spatial firing in a new environment. Exp Neurol 62:282-297.

Hoh T, Beiko J, Boon F, Weiss S, Cain DP (1999) Complex behavioral strategy and reversal learning in the water maze without NMDA receptor-dependent long-term potentiation. J Neurosci 19:RC2 (1-5).

Kentros C, Hargreaves E, Hawkins RD, Kandel ER, Shapiro M, Muller RU (1998) Abolition of long-term stability of new hippocampal place cell maps by NMDA receptor blockade. Science 280:2121-2126.

Kubie JL (1984) A driveable bundle of microwires for collecting single unit data from freely moving rats. Physiol Behav 32:115-118.

Kubie JL, Muller RU, Bostock E (1990) Spatial firing properties of hippocampal theta cells. J Neurosci 10:1110-1123.

Mayford M, Wang J, Kandel ER, O'Dell TJ (1995) CamKII regulates the frequency-response function of hippocampal synapses for the production of both LTP and LTD. Cell 81:891-904.

McHugh TJ, Blum KI, Tsien JZ, Tonegawa S, Wilson MA (1996) Impaired hippocampal representation of space in CA1-specific NMDAR1 knockout mice. Cell 87:1339-1349.

Morris RG (1989) Synaptic plasticity and learning: selective impairment of learning rats and blockade of long-term potentiation in vivo by the $N$-methyl-D-aspartate receptor antagonist AP5. J Neurosci 9:3040-3057.

Morris RG, Frey U (1997) Hippocampal synaptic plasticity: role in spatial learning or the automatic recording of attended experience? Philos Trans R Soc Lond B Biol Sci 352:1589-1503.

Morris RG, Anderson, E, Lynch GS, Baudry M (1986) Selective impairment of learning and blockade of long-term potentiation by an $N$-methylD-aspartate receptor antagonist, AP5. Nature 319:774-776.

Muller RU, Kubie JL, Ranck Jr JB (1987) Spatial firing patterns of hippocampal complex spike cells in a fixed environment. J Neurosci 7:1935-1950.

O'Keefe J (1976) Place units in the hippocampus of the freely moving rat. Exp Neurol 51:78-109.

O'Keefe J, Dostrovsky J (1971) The hippocampus as a spatial map. Evidence from a freely moving rat. Brain Res 34:171-175.

O'Keefe J, Nadel L (1978) The hippocampus as a cognitive map. Oxford: Clarendon.

Ranck Jr JB (1973) Studies on single neurons in dorsal hippocampal formation and septum in unrestrained rats. Exp Neurol 41:461-555.

Rotenberg A, Mayford M, Hawkins RD, Kandel ER, Muller RU (1996) Mice expressing activated CaMKII lack low frequency LTP and do not form stable place cells in the CA1 region of the hippocampus. Cell 87:1351-1361. 
Saucier D, Cain DP (1995) Spatial learning without NMDA receptordependent long-term potentiation. Nature 378:186-189.

Silva AJ, Stevens CF, Tonegawa S, Wang Y (1992a) Deficient hippocampal long-term potentiation in alpha-calcium-calmodulin kinase II mutant mice. Science 257:201-206.

Silva AJ, Paylor R, Wehner JM, Tonegawa S (1992b) Impaired spatial learning in alpha-calcium-calmodulin kinase II mutant mice. Science 257:206-211.

Steele RJ, Morris RG (1999) Delay-dependent impairment of a matchingto-place task with chronic and intrahippocampal infusion of the NMDAantagonist D-AP5. Hippocampus 9:118-136.

Taube JS, Muller RU, Ranck Jr JB (1990) Head-direction cells recorded from the postsubiculum in freely moving rats. I. Description and quantitative analysis. J Neurosci 10:420-435.

Tsien JZ, Huerta PT, Tonegawa S (1996) The essential role of hippocampal CA1 NMDA receptor-dependent synaptic plasticity in spatial memory. Cell 87:1327-1338.

Wilson MA, McNaughton BL (1993) Dynamics of the hippocampal ensemble code for space. Science 261:1055-1058.

Zamanillo D, Sprengel R, Hvalby O, Jensen V, Burnashev N, Rozov A, Kaiser KM, Koster HJ, Borchardt T, Worley P, Lubke J, Frotscher M, Kelly PH, Sommer B, Andersen P, Seeburg PH, Sakmann B (1999) Importance of AMPA receptors for hippocampal synaptic plasticity, but not for learning. Science 280:1805-1811. 